\title{
Mixing Evaluation in the RH Process Using Mathematical Modelling
}

\author{
Satish Kumar AJMANI, Sukanta K. DASH, ${ }^{1)}$ Sanjay CHANDRA and Chaitanya BHANU \\ Tata Steel, Jamshedpur 831001, India. \\ 1) Indian Institute of Technology, Kharagpur, 721302 , India.
}

E-mail: sdash@mech.iitkgp.ernet.in

(Received on May 19, 2003; accepted in final form on August 25, 2003)

\begin{abstract}
Mixing phenomena in a $\mathrm{RH}$ process has been studied numerically by solving the Navier Stokes equations along with the species concentration equation in a cartesian coordinate system comprising the geometry of the ladle and the snorkel fitted to it. The solution of the species concentration equation has been utilized to compute the mixing time in the $\mathrm{RH}$ ladle under different flow conditions. The numerical procedure and solution algorithm has been first verified by comparing the numerically obtained tracer dispersion curve, with the actual plant measurement, which agrees fairly well with each other. Mixing time for the $\mathrm{RH}$ process has been computed for different downleg snorkel size, snorkel immersion depth (SID) and steel velocity within the downleg and a non-dimensional mixing time correlation has been developed for the $\mathrm{RH}$ ladle taking the above three pertinent input parameters into considerations. The correlated non-dimensional mixing time equation predicts fairly well the computed result as well as the actual mixing time being observed in the plant.
\end{abstract}

KEY WORDS: RH-Degasser; mathematical model; mixing time; downleg snorkel size; snorkel immersion depth.

\section{Introduction}

The RH (Ruhrstal Heraeus) Degasser is one of the various vacuum degassing processes which has gained widespread acceptance worldwide for the treatment of molten steel for removal of various dissolved impurities. The RH process, which was originally developed for removal of hydrogen from steel, is now being utilized for decarburisation, deoxidation and composition control. In addition to providing effective degassing this process also provides an effective means of agitating the bath.

The RH process as shown in Fig. 1 is carried out in a refractory lined vessel. The vessel is connected to a system of vacuum pumps capable of obtaining as low as $67 \mathrm{~Pa}(0.5$ torr) vacuum. The vessel has two refractory lined tubes called snorkels, which are used as conduit to circulate steel between the vessel and the ladle. A ladle containing nondeoxidized liquid steel is placed under the vessel. The process starts by lifting the ladle or lowering the RH vessel until the snorkels penetrate the slag layer and get immersed in the steel. In the present case the RH vessel is lowered down. The vessel is then evacuated to a low pressure. Atmospheric pressure forces steel into the lower part of the vessel. Argon or nitrogen lift gas is introduced into one of the snorkels (the upleg snorkel) and the lift gas causes the steel to rise in the upleg snorkel. The steel recirculates through the vessel and returns to the ladle through the other snorkel, called the downleg snorkel. Throughout the treatment, the ladle serves as a reservoir of the liquid steel, while decarburization and degassing of steel takes place inside the vacuum vessel where the steel is exposed to a reduced pressure. During the final treatment stages, deoxidizers and ferro-alloys are added to the steel in the vessel. After the steel is properly treated, the vessel returns to atmospheric pressure and the ladle is then lowered or vessel raised and the ladle sent to the caster.

It has been reported in the literature ${ }^{1)}$ and also found during the normal operation of the RH degasser that the inner size of the downleg snorkel decreases significantly over a period of few days. This may be attributed to the deposition of slag. The size of the downleg snorkel may decrease from existing $450 \mathrm{~mm}$ to around $225 \mathrm{~mm}$. It has been shown in the literature ${ }^{1)}$ that clogging of downleg snorkel, reduces the mixing of ferro-alloys in the RH ladle. The incomplete mixing of ferro-alloys in the ladle may lead to undesirable steel chemistry. In order to understand the mixing phenomena in the RH ladle, the study on fluid flow and mixing in the RH ladle has been taken up in the present work.

The objective of this work was to understand the fluid flow phenomena and compute mixing time of ferro-alloys in the RH ladle under different operating conditions with respect to compositional homogenization, to optimize the design and operating parameters and develop a dimensionless correlation for prediction of mixing time with respect to different operating conditions. The mathematical model developed is to be validated in the plant.

The parameters chosen for the mixing study in the $\mathrm{RH}$ ladle are shown in Table 1. The downleg velocity is not a 
Table 1. Parameters chosen for mixing study for RH ladle.

\begin{tabular}{|c|c|c|}
\hline $\begin{array}{c}\text { Downleg snorkel } \\
\text { Size }(\mathrm{mm})\end{array}$ & $\begin{array}{c}\text { Snorkel immersion } \\
\text { Depth }(\mathrm{mm})\end{array}$ & Downleg velocity $(\mathrm{m} / \mathrm{s})$ \\
\hline $225,300,450$ & $450,600,750,900$ & $0.8,1.0,1.2$ \\
\hline
\end{tabular}

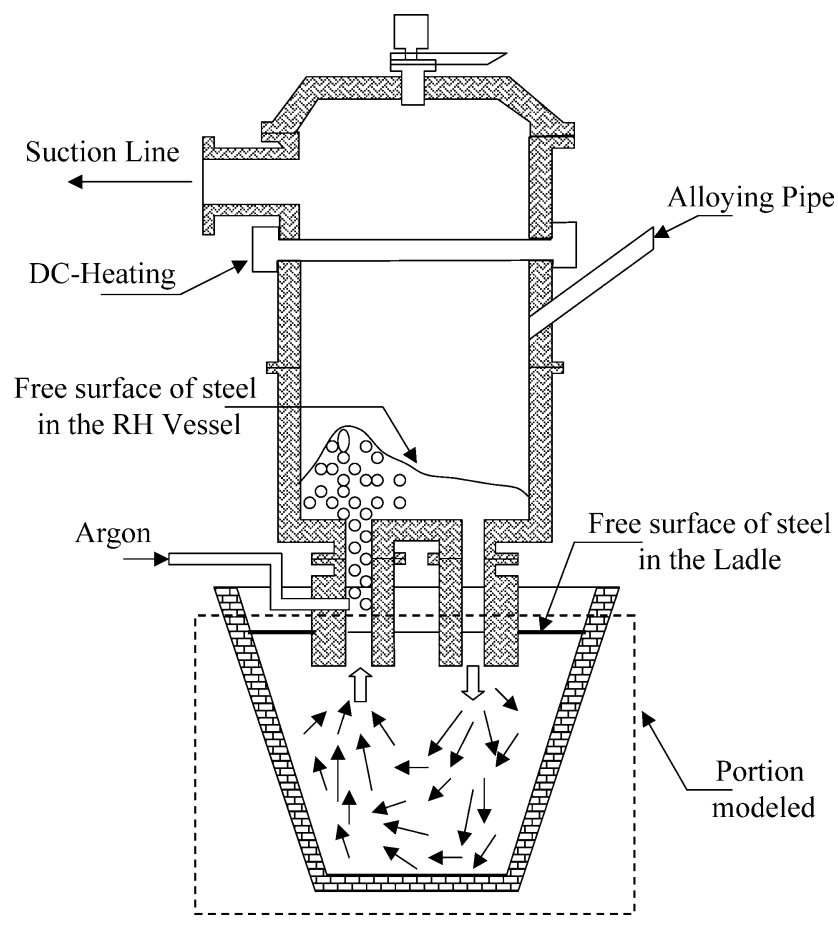

Fig. 1. Schematic diagram of a RH Degasser.

measurable parameter. It has been calculated from the circulation flow rate (CFR) which is defined as the amount of liquid going in or coming out of the $\mathrm{RH}$ degasser per unit time. The CFRs for different downleg velocities and downleg sizes can be computed from Eq. (9).

\section{Methodology}

Earlier, Nakanishi et $a l^{2)}$ as well as Shirabe et al. ${ }^{3)}$ in their studies on fluid flow in RH ladle used a two dimensional model. They found two major circulating loops; one in the region below the downleg and the other major recirculation flow between the upleg and the downleg snorkels. In some of the recent studies by Szatkowski et al., ${ }^{1)}$ Tsujino et $a{ }^{4} .^{4)}$ and Kato et $a l^{7)}$ it has been shown that by pass flow from downleg to upleg is unlikely to occur in the RH ladle even at a reduced circulation rate or reduced distance between upleg and downleg snorkels. The by pass flow observed in the above studies may be the result of using a two dimensional model to represent a three dimensional flow in the ladle. Hence a three dimensional numerical model was developed for the RH ladle and snorkels (as shown in Fig. 1) to investigate the steel flow and mixing in the RH ladle.

The following assumptions were made while formulating the problem:

i) The RH ladle was considered to be cylindrical (the actual ladle has a very minor taper)

ii) It was considered that there is no slag at the top of steel in the ladle.

iii) The top surface of steel was assumed to be flat i.e. no surface fluctuations. iv) It was assumed that the addition of ferro-alloys does not affect the flow field in the RH ladle.

The governing differential equations for a steady state, turbulent flow in a RH ladle is described as follows:

Continuity

$$
\frac{\partial}{\partial x_{i}}\left(\rho U_{i}\right)=0
$$

Momentum

$$
\frac{D\left(\rho U_{i}\right)}{D t}=-\frac{\partial p}{\partial x_{i}}+\frac{\partial}{\partial x_{j}}\left[\mu\left\{\frac{\partial U_{i}}{\partial x_{j}}+\frac{\partial U_{j}}{\partial x_{i}}\right\}-\overline{\rho u_{i} u_{j}}\right]
$$

Turbulent kinetic energy ${ }^{5,6}$

$$
\frac{D(\rho k)}{D t}=D_{k}+\rho P-\rho \varepsilon
$$

Rate of dissipation of $k$

$$
\frac{D(\rho \varepsilon)}{D t}=D_{\varepsilon}+C_{1} \rho P \frac{\varepsilon}{k}-C_{2} \frac{\rho \varepsilon^{2}}{k}
$$

Concentration

$$
\frac{\partial}{\partial t}(\rho C)+\frac{\partial}{\partial x_{i}}\left(\rho u_{i} C\right)=\frac{\partial}{\partial x_{i}}\left(\frac{\mu}{\sigma_{\mathrm{c}}} \frac{\partial C}{\partial x_{i}}\right)
$$

Where,

$$
\begin{aligned}
\overline{u_{i} u_{j}} & =\frac{2}{3} k \delta_{i j}-v_{\mathrm{t}}\left(\frac{\partial U_{i}}{\partial x_{j}}+\frac{\partial U_{j}}{\partial x_{i}}\right) \\
v_{\mathrm{t}} & =0.09 \frac{k^{2}}{\varepsilon} \\
D_{\phi} & =\frac{\partial}{\partial x_{j}}\left[\left(\mu+\frac{\mu_{\mathrm{t}}}{\sigma_{\phi}}\right) \frac{\partial \phi}{\partial x_{j}}\right] \\
P & =-\overline{u_{i} u_{j}} \frac{\partial U_{i}}{\partial x_{j}}
\end{aligned}
$$

Constants

$$
C_{1}=1.44, \quad C_{2}=1.92, \quad \sigma_{\mathrm{c}}=1.0, \quad \sigma_{k}=1.0, \quad \sigma_{\varepsilon}=1.0
$$

The RH ladle has a plane of symmetry passing through the center of the snorkels. Therefore only half of the ladle was considered for modeling of the RH mixing process.

The boundary conditions given for the fluid are as follows:

- At the ladle and the snorkels wall no slip boundary condition was considered and the wall function was employed. ${ }^{9)}$

- At the plane of symmetry the shear stress is put to be zero.

- At the top surface of liquid steel also symmetry boundary condition was taken.

- At the entrance of downleg snorkel a constant liquid steel velocity was given as input. 
- At the exit of upleg snorkel, zero pressure condition was considered which means that the fluid is leaving the domain at an external relative pressure of 0.0 .

- Kinetic energy $(k)$ and energy dissipation rate ${ }^{9)}(\varepsilon)$ values used were:

$$
k=\frac{1}{2}(0.02 \times \text { inlet velocity })^{2}
$$

for turbulence intensity of 0.02

$$
\varepsilon=\frac{0.09 k^{2}}{10 \times \text { laminar kinematic viscosity }}
$$

The boundary conditions for tracer addition were as follows:

- The gradient of tracer concentration was zero at the ladle and snorkels wall, at the plane of symmetry and at the exit of the upleg snorkel.

- Tracer concentration at the entrance of the downleg snorkel was given by:

$$
C_{\mathrm{e}}(t)=\left\{\begin{array}{ll}
C_{i} & \text { for } 0<t \leq t_{i} \\
0 & \text { for } t_{i}<t \leq d t \\
C_{\mathrm{u}} & \text { for } t>d t
\end{array}\right\}
$$

where $d t$ is the vessel retention time calculated from the following relation:

$$
d t=V / Q, \quad \text { where } \quad Q=\frac{\pi D_{\mathrm{d}}^{2}}{4} V_{\mathrm{d}}
$$

As can be seen from the above equations, steel circulation through the RH vessel was considered in the calculations. The tracer concentration was $C_{i}$ for the tracer injec- tion time, $0<t \leq t_{i}$ and it is reduced to zero for the time interval $t_{i}<t \leq d t$ and it is set to $C_{\mathrm{u}}$ for $t>d t$. $C_{\mathrm{u}}$ was the average concentration at the outlet of the upleg snorkel. The concentration of the tracer coming out from the upleg was used at the downleg after a delay time equal to the vessel retention time, $d t$. The feedback flow of the tracer through the vessel made the simulations more realistic.

Tsujino et $\mathrm{al}^{4)}$ have used cylindrical coordinates to describe a ladle. However, cylindrical coordinates used to describe a ladle were found to give an inaccurate representation of the solid boundaries in the snorkels. Since the flow inside and around the snorkels was a critical part of the model a more accurate representation of the computational domain by cartesian coordinate was used for simulation. Control volume of $58 \times 25 \times 22(X \times Y \times Z)$ as shown in Fig. 2, was used to describe the ladle in a cartesian system. The dimensions of the computational domain are also shown in Fig. 2. Fine grids were employed in the snorkels and boundaries where high gradients of velocity and concentration were expected. The cell "blocking off" method was used to convert the computational domain into the required shape of ladle and snorkels. The front and top of the computational domain as well as six locations for monitoring the tracer concentration are shown in Fig. 2.

An academic version of the CFD software (Phoenics) was used to perform the above computations. First the steady state flow field was obtained for a particular set of condition. A fluid flow simulation takes about 1200 sweeps and hours of computational time on a P3 machine to get the converged solution. The solution was considered converged when sum of the absolute values of the imbalances in the Finite Volume Equation (FVE) fall below a user set reference value of $1.0 \mathrm{E}-06$ for all the variables. Further running of the program did not change the solution at all. Once the flow field in the ladle was determined, the boundary condi-

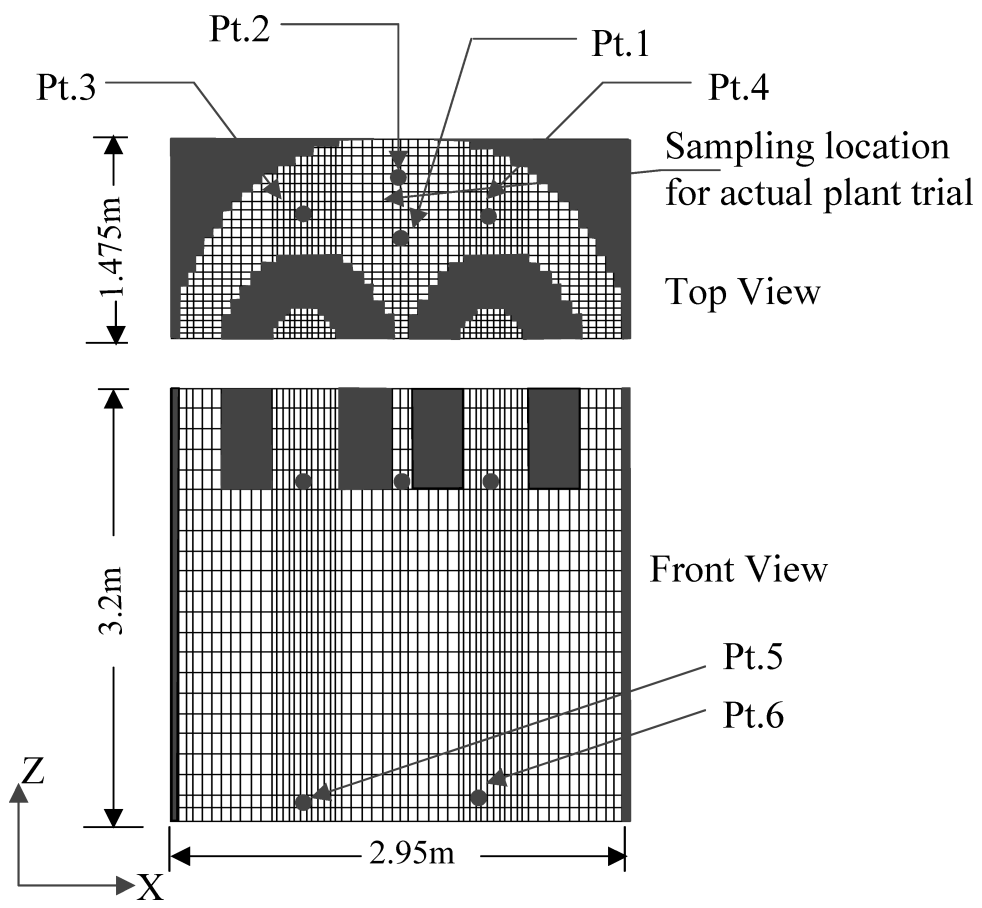

Fig. 2. Front and top view of the RH ladle with grid arrangement and location of the tracer monitoring points. Grid size $=58 \times 25 \times 22$. 
tions were modified for the tracer dispersion study. To incorporate the average concentration of tracer at the outlet of upleg as input to the downleg snorkel, after a delay time of " $d t$ " which was the vessel retention time, GROUND file in the PHOENICS was modified. The Ground file is a blank subroutine provided for the user to insert his own coding. The modified program was run for transient condition to predict the tracer concentration in the entire ladle and a plot of the tracer at six different locations in the ladle was also obtained to compute the mixing time. Grid independency test was also carried out for each geometry and condition. Number of control volumes in the ladle was increased to $100 \times 45 \times 44$ and it was observed that there was a difference of $0.5 \%$ in the mixing time compared to the coarse grid. So for the ladle we always used the coarse grid in order to keep the computational time low.

\section{Results and Discussion}

The mathematical model developed for the RH-ladle was run for different conditions as mentioned in Table 1. Simulations were carried out to investigate the effect of three different downleg snorkel sizes of 450, 300 and 225 $\mathrm{mm}$, four different snorkel immersion depths of 450,600 , 750 and $900 \mathrm{~mm}$ and three different liquid steel velocities in the downleg of $0.8,1.0$ and $1.2 \mathrm{~m} / \mathrm{s}$, on mixing in the $\mathrm{RH}$ ladle. In this study the dissolution of ferro-alloys was not considered while computing the mixing time. The time for ferro-alloys dissolution must be added to the mixing time computed to get the actual time of mixing of ferro-alloys in the RH ladle.

Figure 3 shows the steel flow distribution in the ladle for downleg size of $450 \mathrm{~mm}$, snorkel immersion depth of 450 $\mathrm{mm}$ and downleg velocity of $1.0 \mathrm{~m} / \mathrm{s}$. This is the central vertical $z-x$ plane passing through the center of both the upleg and downleg snorkels. The figure shows the presence

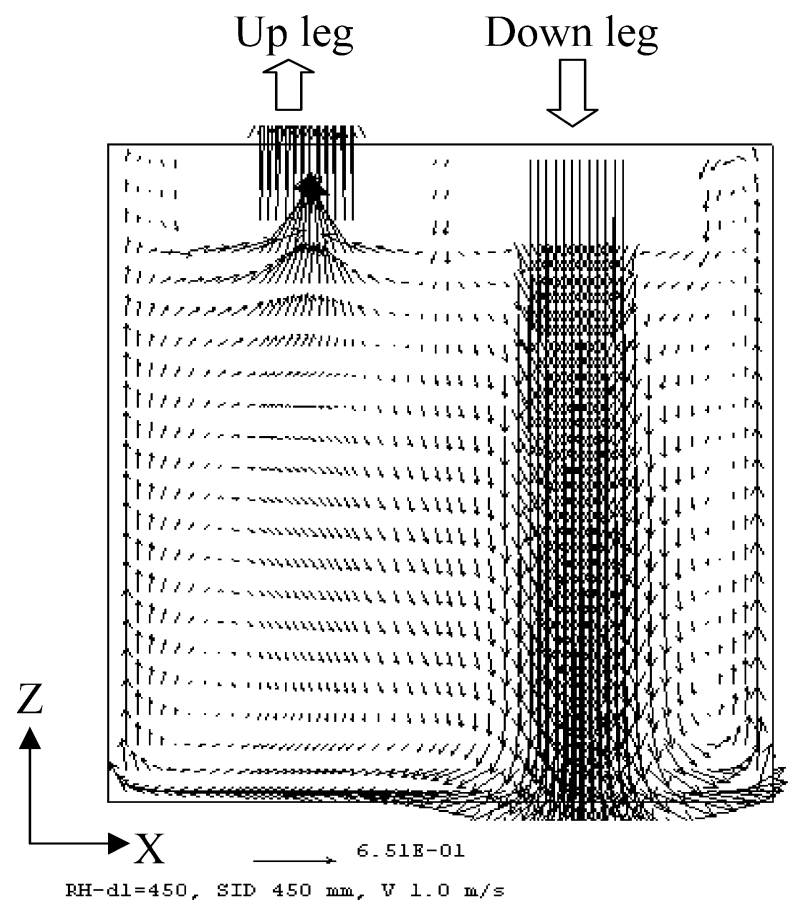

Fig. 3. Velocity vectors in $X-Z$ plane of $\mathrm{RH}$ ladle for downleg $450 \mathrm{~mm}$, SID $450 \mathrm{~mm}$ and downleg velocity $1.0 \mathrm{~m} / \mathrm{s}$. of two prominent circulation zones-one between the downleg stream and the nearest ladle wall and the other away from the downleg stream. Liquid steel within the circulation was slow moving. Similar kind of flow pattern was also observed by other investigators. ${ }^{1,4,7,8)}$ Figures $\mathbf{4}$ and $\mathbf{5}$ show the flow pattern observed in the vertical $y-z$ plane passing separately through the center of downleg and upleg snorkels respectively. Two very prominent circulation zones were observed around the downleg stream as shown in Fig. 4. These circulation zones mix up and the velocity vectors decrease as one moves from downleg to the upleg snorkel as depicted in Fig. 5. Figure 6 shows the flow pattern at the bottom of the ladle. The flow of steel was very fast at the bottom of the ladle. It hits the side of the ladle and came up along the sides. Figures $\mathbf{7}$ and $\mathbf{8}$ show the flow pattern at the cross-sectional planes: one just below the snorkels and other at the top of the ladle. Figure 7 clearly shows that the

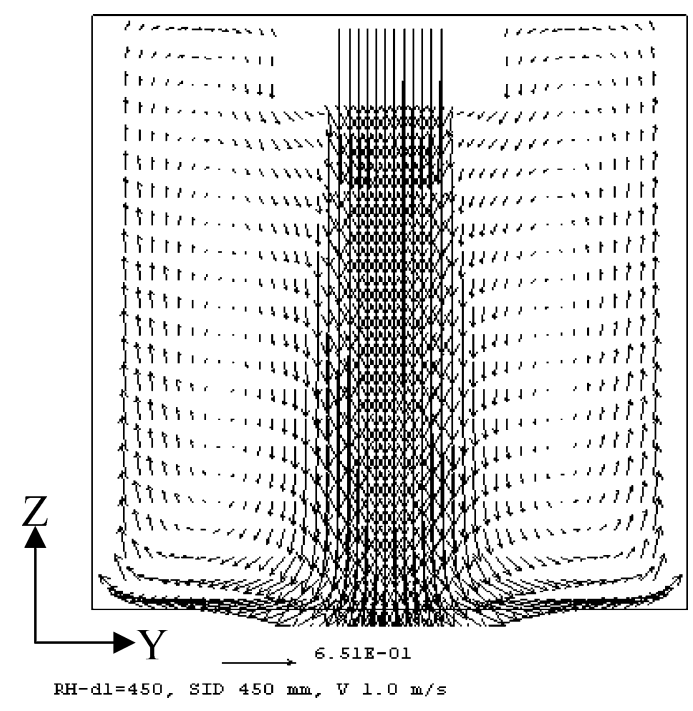

Fig. 4. Velocity vectors in vertical $Y-Z$ plane of RH ladle passing through downleg snorkel for conditions: downleg snorkel $450 \mathrm{~mm}$, SID $450 \mathrm{~mm}$ and downleg velocity 1.0 $\mathrm{m} / \mathrm{s}$.

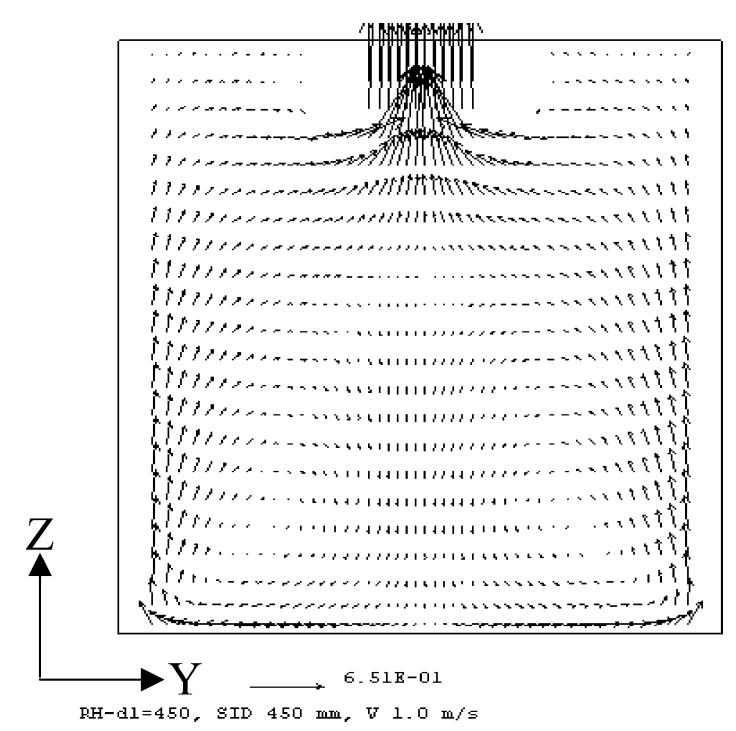

Fig. 5. Velocity vectors in vertical $Z-Y$ plane of $\mathrm{RH}$ ladle passing through upleg snorkel for conditions: downleg snorkel $450 \mathrm{~mm}$, SID $450 \mathrm{~mm}$ and downleg velocity 1.0 $\mathrm{m} / \mathrm{s}$. 


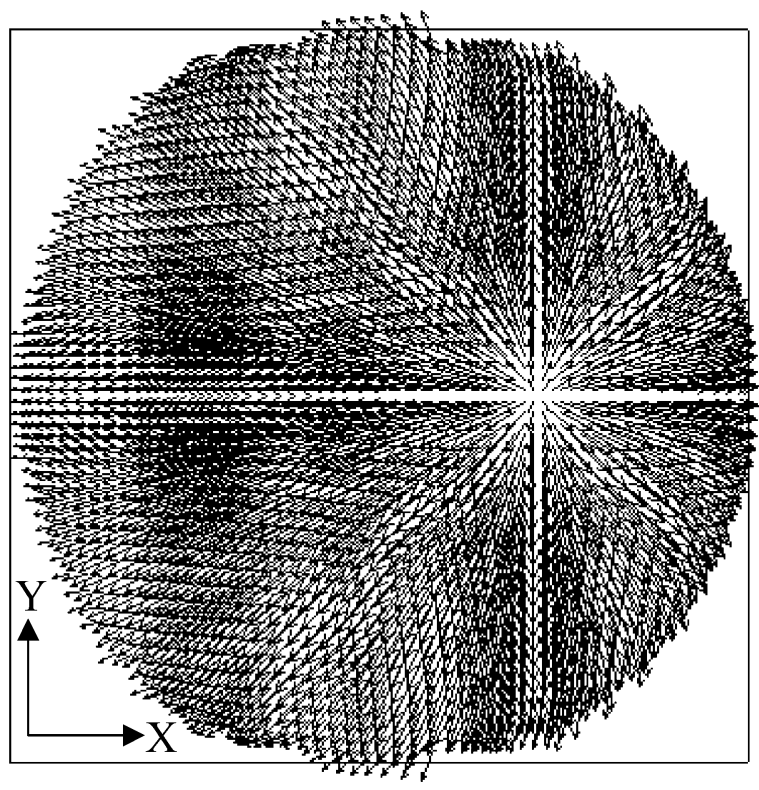

$6.51 \mathrm{E}-01$

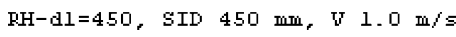

Fig. 6. Velocity vectors in bottom $Y-X$ plane of $\mathrm{RH}$ ladle for conditions: downleg snorkel $450 \mathrm{~mm}$, SID $450 \mathrm{~mm}$ and downleg velocity $1.0 \mathrm{~m} / \mathrm{s}$.

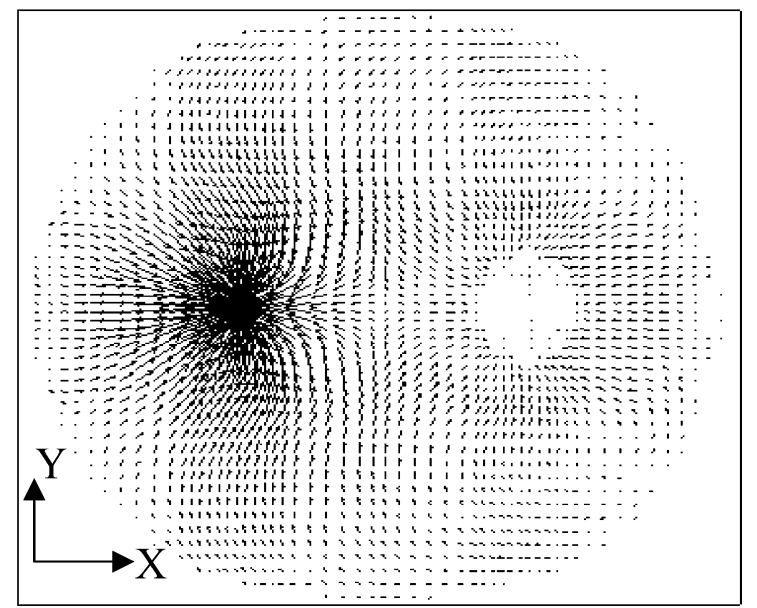

$6.51 \mathrm{E}-01$

$\mathrm{PH}-\mathrm{dl}=450, \operatorname{SID} 450 \mathrm{~mm}, \mathrm{~V} 1.0 \mathrm{~m} / \mathrm{s}$

Fig. 7. Flow vectors in $Y-X$ plane just below the snorkels of $\mathrm{RH}$ ladle for conditions: downleg snorkel $450 \mathrm{~mm}$, SID 450 $\mathrm{mm}$ and downleg velocity $1.0 \mathrm{~m} / \mathrm{s}$.

flow around the upleg snorkel, approaching it from all the sides, try to come towards the upleg. It also shows the flow close to the downleg snorkel is directed towards the downleg only. Such a phenomenon takes place due to the local suction of the fluid from the downleg in to the ladle and also from the upleg in to the vessel. Figure 8 shows the top most plane in the $z$ direction. It shows that most of the velocity vectors are aligned towards the downleg snorkel to go along with the stream which was coming out from the downleg. All the above Figures-Figs. 3 to 8 are for the same operating conditions of downleg velocity of $1.0 \mathrm{~m} / \mathrm{s}$, SID of $450 \mathrm{~mm}$, and downleg snorkel size of $450 \mathrm{~mm}$. Similarly, the fluid flow predictions were made for other snorkel sizes, different SIDs and different downleg veloci-

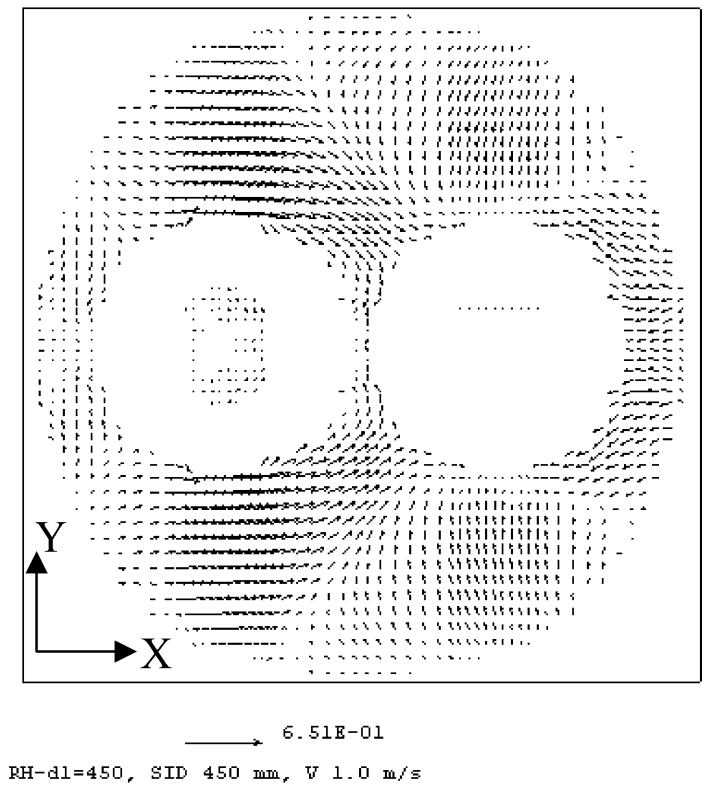

Fig. 8. Velocity vectors in top $Y-X$ plane of $\mathrm{RH}$ ladle for conditions: downleg snorkel $450 \mathrm{~mm}$, SID $450 \mathrm{~mm}$ and downleg velocity $1.0 \mathrm{~m} / \mathrm{s}$.

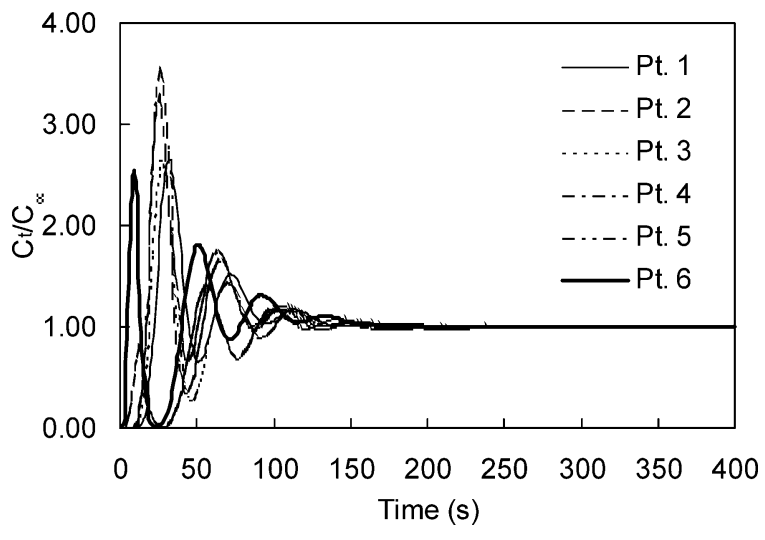

Fig. 9. Variation of tracer concentration at six different points in the ladle at downleg size $450 \mathrm{~mm}$, snorkel immersion depth $450 \mathrm{~mm}$ and downleg velocity $1.0 \mathrm{~m} / \mathrm{s}$.

ties.

Computations for downleg sizes of 300 and $225 \mathrm{~mm}$ did not show significant difference in the flow field. However, the strength of recirculation was found to be stronger for the case of $450 \mathrm{~mm}$ downleg size as because this size of downleg brings the highest linear momentum in to the ladle.

Once the mathematical model was ready with fluid flow predictions, it was modified to run for tracer dispersion study by putting some tracer in the downleg for $5 \mathrm{~s}$. The problem was changed from a steady state to a transient one. The boundary conditions for tracer injection were changed accordingly. The concentration of tracer was monitored simultaneously at six different locations in the ladle as shown in Fig. 2. The computation was run for $900 \mathrm{~s}$ and the concentration of tracer was monitored after every one second. Figures 9 and $\mathbf{1 0}$ show the variation of concentration ratio $\left(C_{t} / C_{\infty}\right)$ with time at six different locations in the $\mathrm{RH}$ ladle for two different operating conditions. It can be seen from the figures that the concentration at all the points in the 


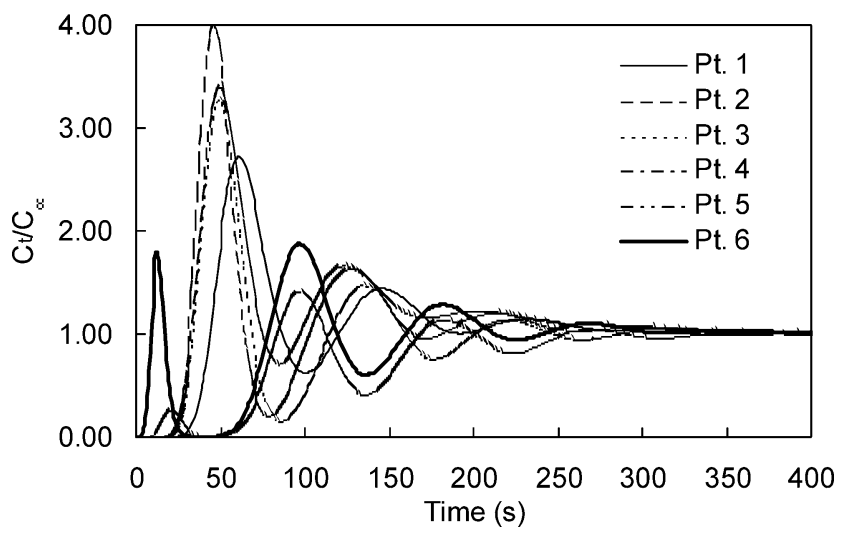

Fig. 10. Variation of tracer concentration at six different points in the ladle at downleg size $225 \mathrm{~mm}$, snorkel immersion depth $450 \mathrm{~mm}$ and downleg velocity $1.0 \mathrm{~m} / \mathrm{s}$.

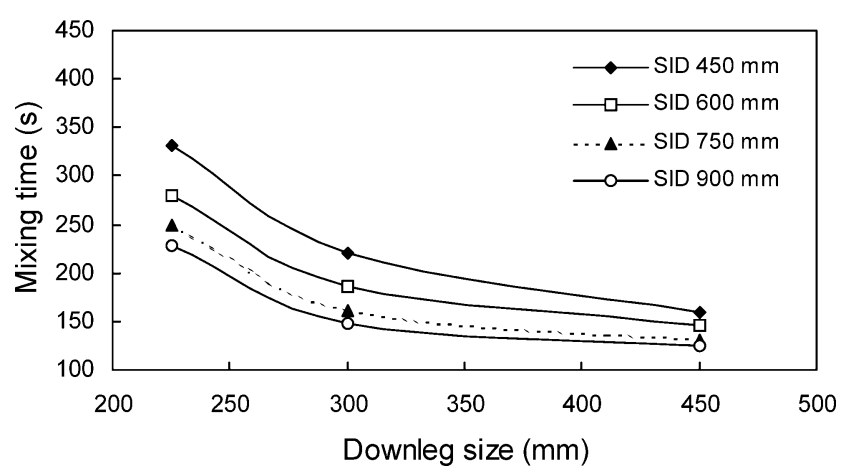

Fig. 11. Mixing time $v s$. snorkel size at different snorkel immersion depth (SIDs) and downleg velocity of $1.0 \mathrm{~m} / \mathrm{s}$.

ladle become almost the same after sometime, which can be told to be the mixing time. It can be seen that (Figs. 9 and 10) tracer monitoring point at the lower part of the ladle started monitoring the tracer concentration first (Pt. 5 and 6 ). The tracer concentration increased first, reached a peak value and then decreased slowly. Meanwhile, the tracer monitoring point at the upper part of the ladle also started monitoring the concentration. At this point also, the tracer concentration increased slowly, reached a peak value and then decreased. When the tracer concentration at the upper point was at the highest, at the lower point the concentration was at the lowest. Similar kind of behavior was observed for other conditions also. It is clear from the figure that the concentration throughout the ladle became homogeneous after the mixing time. Since it was very difficult to achieve $100 \%$ mixing, the time when the tracer concentration reached the band of $\pm 5 \%$ of the final concentration $\left(C_{\infty}\right)$, was considered as the mixing time. This time corresponds to the time needed for the complete homogenization of ferro-alloys in the ladle. Similarly, the computations were carried out for the other conditions also and the mixing time was computed. Figure 11 shows the variation of mixing time against snorkel size at four different SIDs at a downleg velocity of $1.0 \mathrm{~m} / \mathrm{s}$. As is obvious from the Figure, the mixing time increased with the decrease of snorkel size at all the SIDs. But the increase in mixing time was very sharp at a particular value of downleg size and below. This downleg size at which mixing time increased sharply is known as critical downleg size. It can also be observed from the figure that mixing time decreased with the in-

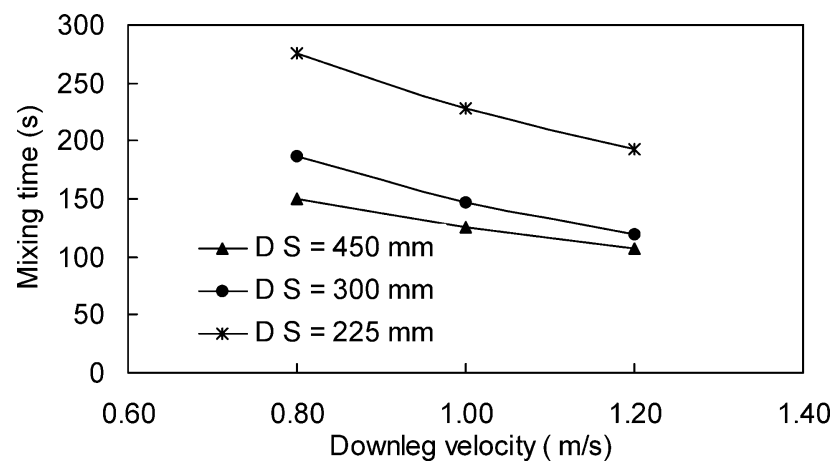

Fig. 12. Variation of mixing time with downleg velocity at different downleg sizes and snorkel immersion depth of $900 \mathrm{~mm}$.

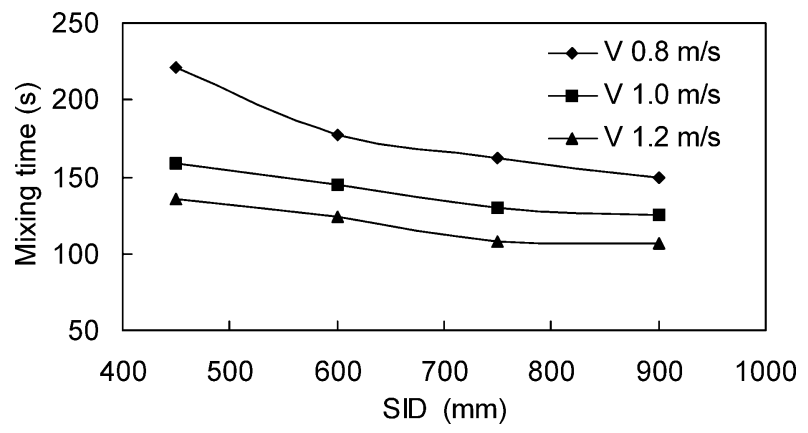

Fig. 13. Variation of mixing time with snorkel immersion depth for different downleg velocities at a downleg size of 450 $\mathrm{mm}$

crease of SID, higher the SID lower is the mixing time. As the SID increases the flow injection point into the ladle increases and the jet impingement on the bottom of the ladle becomes stronger so the strength of recirculation inside the ladle increases which causes the mixing to be faster. It can further be noticed that as the SID increased from 450 to $600 \mathrm{~mm}$, mixing time decreased to a larger extent but when the SID increased further from 750 to $900 \mathrm{~mm}$, the extent of decrease in the mixing time was less. Similar figures were also obtained at downleg velocity of 0.8 and $1.2 \mathrm{~m} / \mathrm{s}$. Mixing time was also plotted with respect to different downleg velocities. Figure 12 shows the variation of mixing time with downleg velocity at different downleg snorkel sizes and SID of $900 \mathrm{~mm}$. It can be seen that mixing time decreased with the increase of downleg velocity at all the downleg sizes. Mixing time was found to be much higher with downleg snorkel size of $225 \mathrm{~mm}$ compared to mixing time with downleg snorkel size of $450 \mathrm{~mm}$. The momentum of liquid stream coming out from the downleg snorkel size of $225 \mathrm{~mm}$ was low compared to downleg snorkel size of $450 \mathrm{~mm}$. The large momentum, which is transferred into the ladle will be converted in to a kind of recirculatory flow. So it is expected that a jet with higher momentum will create stronger recirculation in the ladle than a jet with lower linear momentum. So the mixing time will be less in case of higher snorkel size.

Figure 13 shows the variation of mixing time with SIDs at different downleg velocities for a downleg snorkel size of $450 \mathrm{~mm}$. Mixing time decreased almost linearly with the increase of SID at all the downleg velocities. As the SID in- 
creases the impact of the jet on the bottom of the RH also increases and this creates a stronger recirculation within the $\mathrm{RH}$ ladle for which mixing time can decrease. It is also expected that if the SID further increases then the impact of the jet on the bottom will still increase but the rising plume will not create a suction effect around the snorkel for which mixing may be spoiled and mixing time can again increase. So it is possible to get an optimum snorkel immersion depth in a particular RH degasser for which mixing time can be the minimum and this can be a future scope of the work. In the work of Ahrenhold and Pluschkell ${ }^{10)}$ it has been shown that the snorkel immersion depth has no effect on mixing time. The reason we suspect is that their experimental set up was too small for the size of the snorkel immersion depth being studied. So mixing time is too small for the setup and it is really difficult to capture the effect of snorkel immersion depth. But in the present computation the size of the RH is very large and in fact the size is the actual size used in the plant. So the variation of mixing time could be captured by changing the SID. However, it should be noted that the variation in mixing time is not very appreciable even in the present computation but clearly the effect of SID exists.

A dimensionless correlation was developed for the prediction of mixing time based on the above results generated under different operating conditions. The dimensionless correlation developed is as follows:

$$
t_{\text {mix }}^{*}(Q / V)=0.0013(\operatorname{Re})^{0.06}(\operatorname{SID} / H)^{-0.52}\left(D_{\mathrm{d}} / D\right)^{1.02}
$$

$R$ square of the above relation was 0.96 .

$\%$ error between actual and predicted mixing time was within $15 \%$ for all the data. $25 \%$ of the data have $\%$ error between 10 to $14 \%$. Rest of the data has \% error less than $10 \%$. Figure 14 shows the predicted and the actual $(t Q / V)$ values for all the data points. The predicted and the actual values matched reasonably well.

The circulation flow rate in the actual plant can be calculated from the following empirical relation developed by Hanna et al. ${ }^{11)}$.

$$
\begin{gathered}
\dot{m}=3.8 \times 10^{-3} D_{\mathrm{u}}^{0.3} D_{\mathrm{d}}^{1.1} G^{0.31} H^{0.5} \\
\rho Q \frac{60}{10^{3}}=\dot{m}(t / \mathrm{min}) \ldots \ldots \ldots
\end{gathered}
$$

Where,

$\mathrm{Q}=$ Volume flow rate $\left(\mathrm{m}^{3} / \mathrm{s}\right)$

$\dot{m}=$ Circulating steel flow rate in vacuum vessel $(t / \mathrm{min})$

$D_{\mathrm{u}}=$ upleg internal diameter $(\mathrm{cm})$

$D_{\mathrm{d}}=$ downleg internal diameter $(\mathrm{cm})$

$G=$ total inert gas injection rate in upleg $(\mathrm{NL} / \mathrm{min})$

$H=$ Nozzle immersion depth $(\mathrm{cm})$

It is to be noted here that in the above empirical relation (Eq. (11)) SI unit is not used by Hanna et al. ${ }^{11)}$ and the reader has to obtain the circulation mass flow rate in tons/min and then convert that to volume flow rate in $\mathrm{m}^{3} / \mathrm{s}$ from Eq. (12). Care has to be taken while using Eq. (11) because the length scales are in centimeter and not in meter. Once the volume flow rate through the down leg is computed from Eq. (12) then the velocity $V_{\mathrm{d}}$ can be computed from Eq. (9) from which, the Reynolds number can be computed. So Eq. (10) can be used in the plant to compute the time for

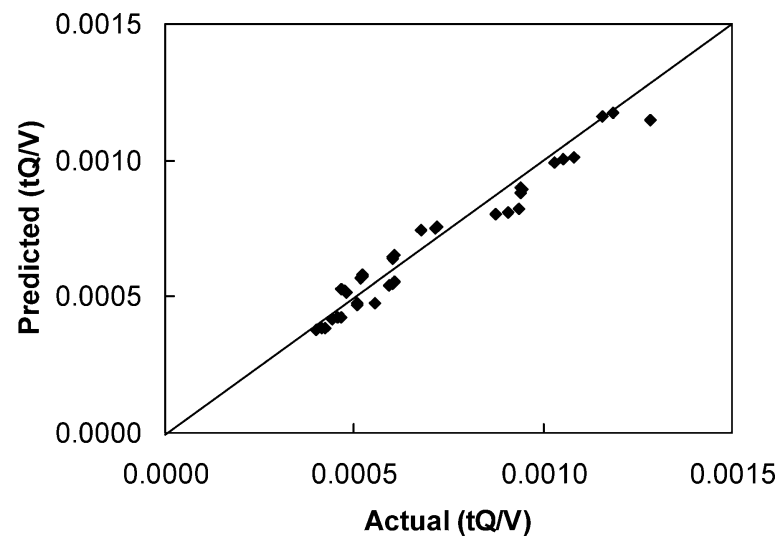

Fig. 14. Predicted $(t Q / V)$ from Eq. (10) $v s$. actual $(t Q / V)$.

Table 2. Details of plant trials at RH Degasser.

\begin{tabular}{|l|c|c|}
\hline \multicolumn{1}{|c|}{ Parameter } & Trial 1 & Trial 2 \\
\hline Snorkel size(mm) & 450 & 450 \\
\hline Downleg velocity $(\mathrm{m} / \mathrm{s})$ & 1.07 & 0.86 \\
\hline SID $(\mathrm{mm})$ & 750 & 534 \\
\hline Vacuum $(\mathrm{Pa})$ & 80 & 280 \\
\hline Argon flow rate $(\mathrm{l} / \mathrm{min})$ & 1200 & 600 \\
\hline Heat size $(\mathrm{t})$ & 130 & 130 \\
\hline
\end{tabular}

mixing in a RH ladle.

\section{- Model Validation}

The mathematical model developed for mixing of ferroalloys was validated by carrying out plant trials at the RHDegasser. To validate the above mathematical model, about $65 \mathrm{~kg}$ of pure copper (purity 99.9\%) cut into small pieces was added into the RH vessel. The ladle capacity was 130 ton and had the same size as has been shown in Fig. 2. Since the melting point of copper is much lower than that of steel and the flow of liquid steel is highly recirculatory and turbulent in the RH vessel, copper will melt in a very short time and mix with the liquid steel. To analyse the change in the copper content in the liquid steel with time, liquid steel samples were taken out manually from the $\mathrm{RH}$ ladle at a very short time intervals (location of sample is shown in Fig. 2). These samples were analysed for copper content in the steel. Two plant trials were carried out for the conditions as shown in Table 2.

The variations of copper content in steel with time for first and second plant trials are shown in Figs. 15 and 16. It can be observed from the figures that the copper content first changes linearly with time, reaches a peak value and after sometime becomes almost constant.

Figure 17 compares the mixing time from the mathematical model with that of the plant trials carried out at the $\mathrm{RH}$ Degasser. Pt. 1 and 2 are two points about $600 \mathrm{~mm}$ below the top surface of liquid steel where the tracer concentration was monitored mathematically. The actual measurements in the plant were also made around points 1 and 2 only as shown in Fig. 2. It can be observed from the figure that the peaks of the tracer concentration do not match with the copper concentration. Since in the actual plant trials it is not possible to monitor the concentration of tracer continuously, peaks of the tracer concentration in the mathematical and in the actual trial may not match. But the overall mixing time obtained mathematically at points 1 and 2 matches 


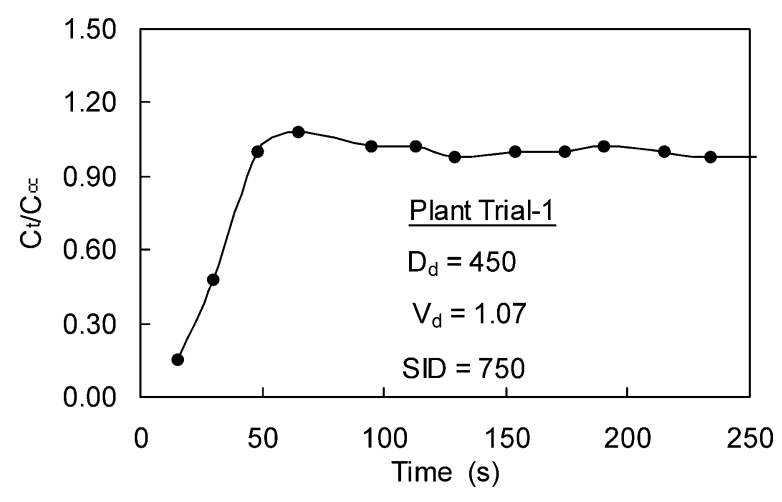

Fig. 15. Variation of copper in liquid steel in ladle with time in the first plant trial.

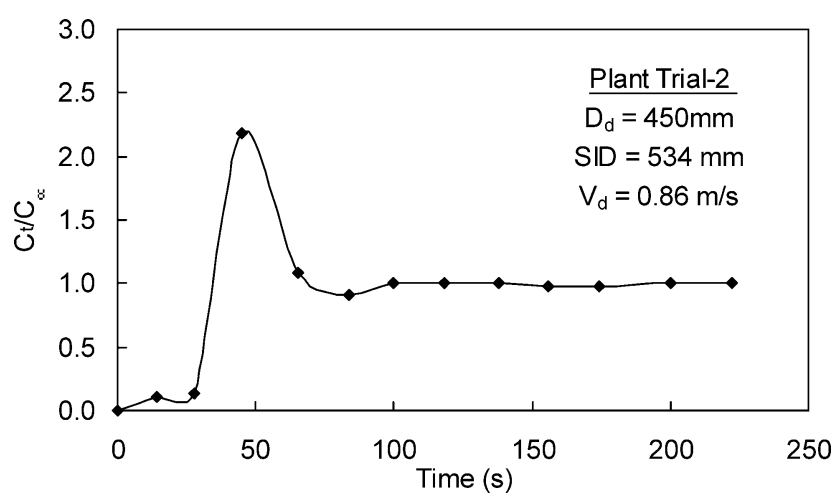

Fig. 16. Variation of copper in liquid steel in ladle with time in second plant trial.

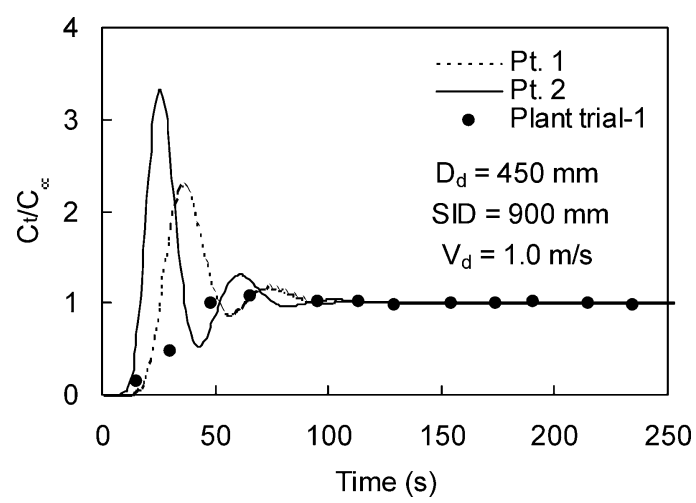

Fig. 17. Comparison of variation of tracer concentration at Pt. 1 and Pt. 2 with the actual plant trial.

very well with the plant results.

The comparison of variation of the tracer computed mathematically at Pt. 1 and Pt. 2 and the second plant trial results are shown in Fig. 18. Pt. 1 and Pt. 2 are the locations that are very close to the actual sample collection point during the plant trial. Here the peak of the tracer concentration computed mathematically was very close to the actual plant trial results. It can be observed from the figure that the computed results and the plant trial results match very closely.

Figure 19 compares the variation of tracer concentration at Pt. 5 and Pt. 6 with the actual plant trial results. Points 5 and 6 are the tracer monitoring points located at the bottom of the ladle as shown in Fig. 2. It can be observed from the figure that the computed results and the plant trials data do

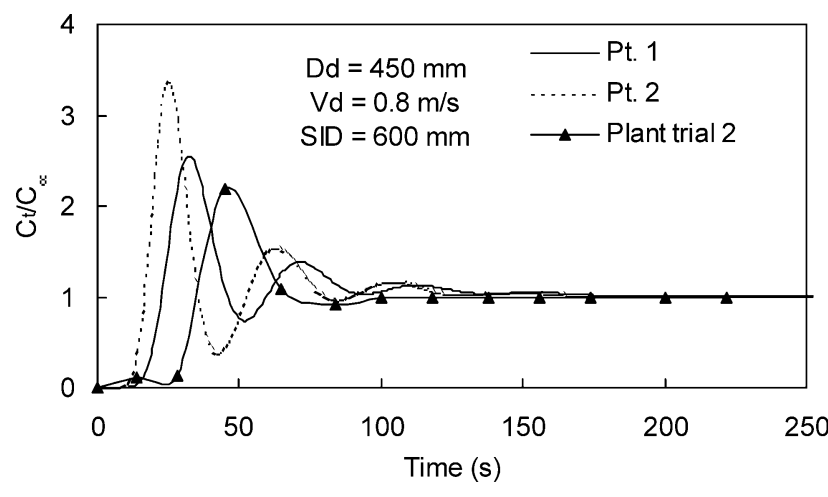

Fig. 18. Comparison of variation of tracer concentration at Pt. 1 and Pt. 2 with the actual plant trial data.

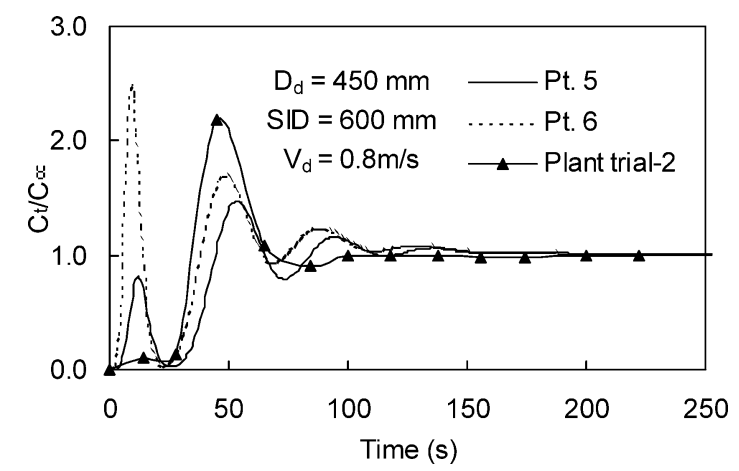

Fig. 19. Comparison of variation of tracer concentration at Pt. 5 and Pt. 6 with the actual plant trial.

not match well. This shows that mixing at Points 1 and 2, which are close to the top of the ladle was much faster compared to Points 5 and 6, which are at the bottom of the ladle. Homogenisation in tracer concentration occurs first at the top of the ladle and then that slowly percolates to the bottom of the ladle. So mixing time can be faster at the top of ladle compared to the bottom if one sees the top and the bottom separately. The correlation for mixing time that has been developed in Eq. (10) takes all the points into accounts and the mixing time based on only the top layer sample analysis can be slightly different from the present correlation because the inside fluid flow of the ladle brings different homogenisation at different parts of the ladle. It can be seen from Fig. 19 that the tracer concentration at Pt. 5 and 6 (bottom of the ladle) has 4 peaks before it attains a steady value compared to the concentration variation of Pt. 1 and 2 (top of the ladle) which have only 3 peaks (Fig. 18).

\section{Conclusions}

(1) A mathematical model has been developed to predict the mixing of ferro-alloys. The effect of downleg size, SIDs and downleg velocities on mixing of ferro-alloys has been studied.

(2) Mixing time increases with decrease of downleg snorkel size and a downleg snorkel size of $300 \mathrm{~mm}$ was found to be the critical downleg size below which mixing time increased sharply.

(3) A dimensionless correlation has been developed for prediction of mixing time in the RH-Degasser.

(4) Mixing time predicted from the mathematical 
model compares favourably well with the plant trial results.

\section{Acknowledgement}

The authors would like to thank Mr. M. N. Poddar and Mr. S. N. Lenka of R\&D and staff of RH control room at LD2 \& SC for their help in conducting the plant trials and RAC 2 lab. of Chemical Department of Scientific Services for their help in carrying out the analysis of a large number of steel samples.

\section{Nomenclature}

$C$ : Concentration

$C_{\mathrm{e}}$ : Concentration at the entrance of the downleg snorkel

$C_{\mathrm{i}}$ : Initial concentration

$C_{\mathrm{u}}$ : Average concentration at the outlet of the upleg snorkel

$C_{\infty}$ : Final concentration $\left(C_{\infty}=\mathrm{C}_{\text {inf }}\right)$

$D_{\mathrm{d}}$ : Downleg snorkel size (DS) (m)

$D$ : Diameter of ladle (m)

$H$ : Height of liquid steel in ladle (m)

$d t$ : Retention time of the vacuum vessel (s)

$k$ : Turbulent kinetic energy $\left(\mathrm{m}^{2} / \mathrm{s}^{2}\right)$

$p$ : Pressure $(\mathrm{Pa})$

$Q: \quad$ Volumetric steel flow rate $\left(\mathrm{m}^{3} / \mathrm{s}\right)$

$t$ : Time (s)

$t_{\text {mix }}:$ Mixing time (s)

$t_{i}:$ Alloy/tracer addition time $(\mathrm{s})$

$u:$ Velocity $(\mathrm{m} / \mathrm{s})$
$V_{\mathrm{v}}: \quad$ Volume of steel in the vessel $\left(\mathrm{m}^{3}\right)$

$V$ : Volume of steel in ladle $\left(\mathrm{m}^{3}\right)$

$V_{\mathrm{d}}$ : Downleg liquid steel velocity $(\mathrm{m} / \mathrm{s})$

$\rho$ : Steel density $\left(\mathrm{kg} / \mathrm{m}^{3}\right)$

$\mu$ : Viscosity of liquid steel $(\mathrm{Pa} \cdot \mathrm{s})$

$\mu_{\mathrm{e}}$ : Effective viscosity of steel $(\mathrm{Pa} \cdot \mathrm{s})$

$\varepsilon$ : Rate of energy dissipation $\left(\mathrm{m}^{2} / \mathrm{s}^{3}\right)$

$\sigma_{\mathrm{c}}:$ Turbulent Schmidt number

Re: $D_{\mathrm{d}}{ }^{*} V_{\mathrm{d}}^{*} \rho / \mu$ : Reynolds number

\section{REFERENCES}

1) M. Szatkowski and M. C. Tsai: ISS Trans., 13 (1992), 33.

2) K. Nakanishi, J. Szekely and C. W. Chang: Ironmaking Steelmaking, 2 (1975), 115

3) K. Shirabe and J. Szekeley: Trans. Iron Steel Inst. Jpn., 23 (1983), 465.

4) R. Tsujino, J. Nakashima, M. Hirai and I. Sawada: ISIJ Int., 29 (1989), 589.

5) B. E. Launder and D. B. Spalding: Appl. Mech. Eng., 3 (1974), 269.

6) Phoenics Easy Flow User Manual, Appendix C, CHAM, London, (1993), C4.

7) Y. Kato, H. Nakato, T. Fujii, S. Ohmiya and S. Takatori: ISIJ Int., 33 (1993), 1088.

8) S. K. Ajmani and S. K. Dash: Tata Search, (A Journal of Technical Advances in Tata Steel), (1999), 85.

9) P. K. Jha and S. K. Dash: Int. J. Numer. Meth. Heat Fluid Flow, 12 (2002), 560.

10) F. Ahrenhold and W. Pluschkell: Steel Res., 70 (1999), 313.

11) R. K. Hanna, T. Jones, R. I. Blake and M. S. Millman: Ironmaking Steelmaking, 21 (1994), No. 1, 37. 